\title{
Suplementary Appendix
}

\section{Price Elasticities}

Following the procedure by Zhen et al. [15], we calculated the compensated (Hicksian) elasticity of demand for good $j$ with respect to the price of good $k$ and expenditure elasticities. Then, using the Slutsky equation, we computed uncompensated (Marshallian) price elasticities (dropped 7 out of 10,485 households/observations with extreme values).

Compensated (Hicksian) elasticity of demand for good $j$ with respect to price of $\operatorname{good} k$ is,

$$
\xi=\varpi^{-1} A+\Omega \varpi-I
$$

where $\xi$ is a $J x J$ matrix of compensated demand elasticities, $\varpi$ is an identity matrix where the ones are replaced by the food group's budget shares, $\Omega$ is an $J x J$ matrix of ones and $I$ is an identity matrix. Expenditure elasticities are calculated as:

$$
\left.\eta=\varpi^{-1}\left(I+B P^{\prime}\right)^{-1} B+1_{j}\right)
$$

where $\eta$ is an $J$ vector of expenditure elasticities and $B$ is the derivative of equation 4 (model corrected by Shonkwiler and Yen 63]) with respect to the real expenditures $y_{l}$, whose $j$ th elements equal $\sum_{r=1}^{3} r b_{i r} y^{r-1}, P$ is the $J X 1$ vector of $\log$ prices, and $1_{j}$ is a $J x 1$ vector of ones.

Uncompensated (Marshallian) price elasticity is recovered from the Slutsky equation,

$$
E=\eta-\xi * S
$$

\section{Welfare Analysis}

Based on the cost function $C\left(p_{0}, u, z, \varepsilon\right)$, we evaluated the cost to an individual of a price change based on Pendakur [55]. In order to obtain that result, we used the log cost of living index as a consumer surplus measure for the price change from $p_{0}$ to $p_{1}$ which, for the cost function, is given by: 


$$
\begin{aligned}
\ln \left(\frac{C\left(p_{1}, u, z, \varepsilon\right)}{C\left(p_{0}, u, z, \varepsilon\right)}\right) & =\sum_{j=1}^{J} w_{0}^{j}\left(\ln p_{1}^{j}-\ln p_{0}^{j}\right) \\
& +\frac{1}{2} \sum_{j=1}^{J} \sum_{k=1}^{J} a^{j k}\left(\ln p_{1}^{j}-\ln p_{0}^{j}\right)\left(\ln p_{1}^{j}-\ln p_{0}^{j}\right)
\end{aligned}
$$

The first term of the equation 8 is the Stone index for the price change, which captures the first order effects driven by expenditure shares. The presence of the second term allows one to explicitly model substitution effects (or second order effects). The welfare calculated by equation 8 is related to the reference household. However, the interpretation of the error terms as unobserved preference heterogeneity allows the estimation of a distribution of welfare, instead of only the average welfare effect.

Finally, based on Lewbel and Pendakur 26, we adjusted our welfare estimations with an equivalence scale for households with different demographic characteristics. These equivalence scales allow inter-household comparisons of the welfare effect. The equivalence scale is given by:

$$
\ln E(p, u, z, e)=\sum_{t=1}^{T} g_{t}^{j} z_{t}+\sum_{t=1}^{T} \sum_{j=1}^{J} \ln p^{j}\left(g_{t}^{j} z_{t}+\varepsilon^{j}\right)+\frac{1}{2} \sum_{j=1}^{J} \sum_{k=1}^{J} a^{j k} \ln p^{j} \ln p^{k}
$$

where $d$ are the coefficients of demographic variables, $z$ is the vector of demographic variables, $p$ is the vector of price index and $A$ are price coefficients.

\section{Supplementary Tables and Figures}

Tables S1 and S2 shows the Marshallian price elasticities for low (quntile 1) and high (quintile 5) income households. Table S3 presents the compensated variation by income quintile assuming different pass through scenarios. 


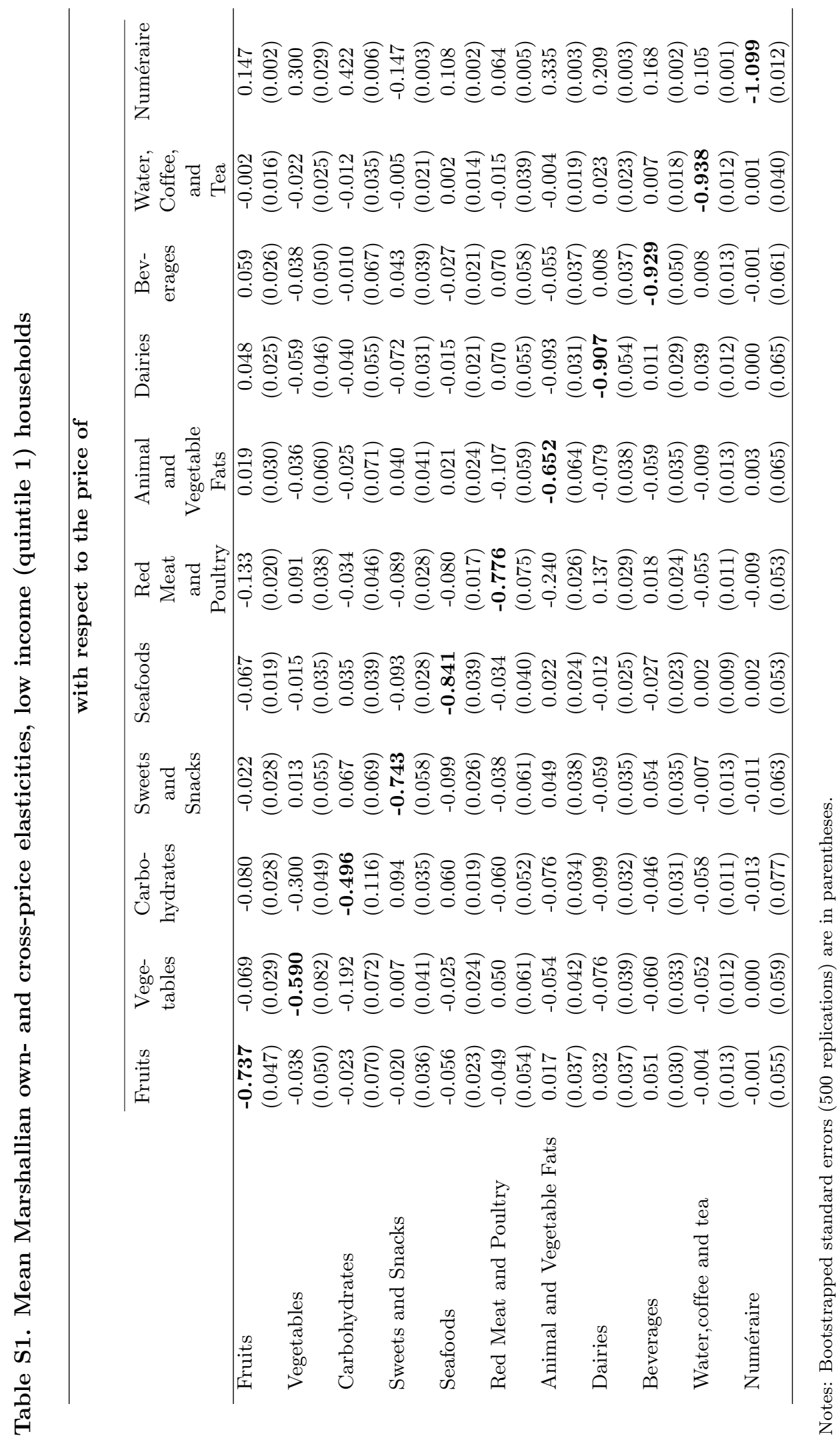




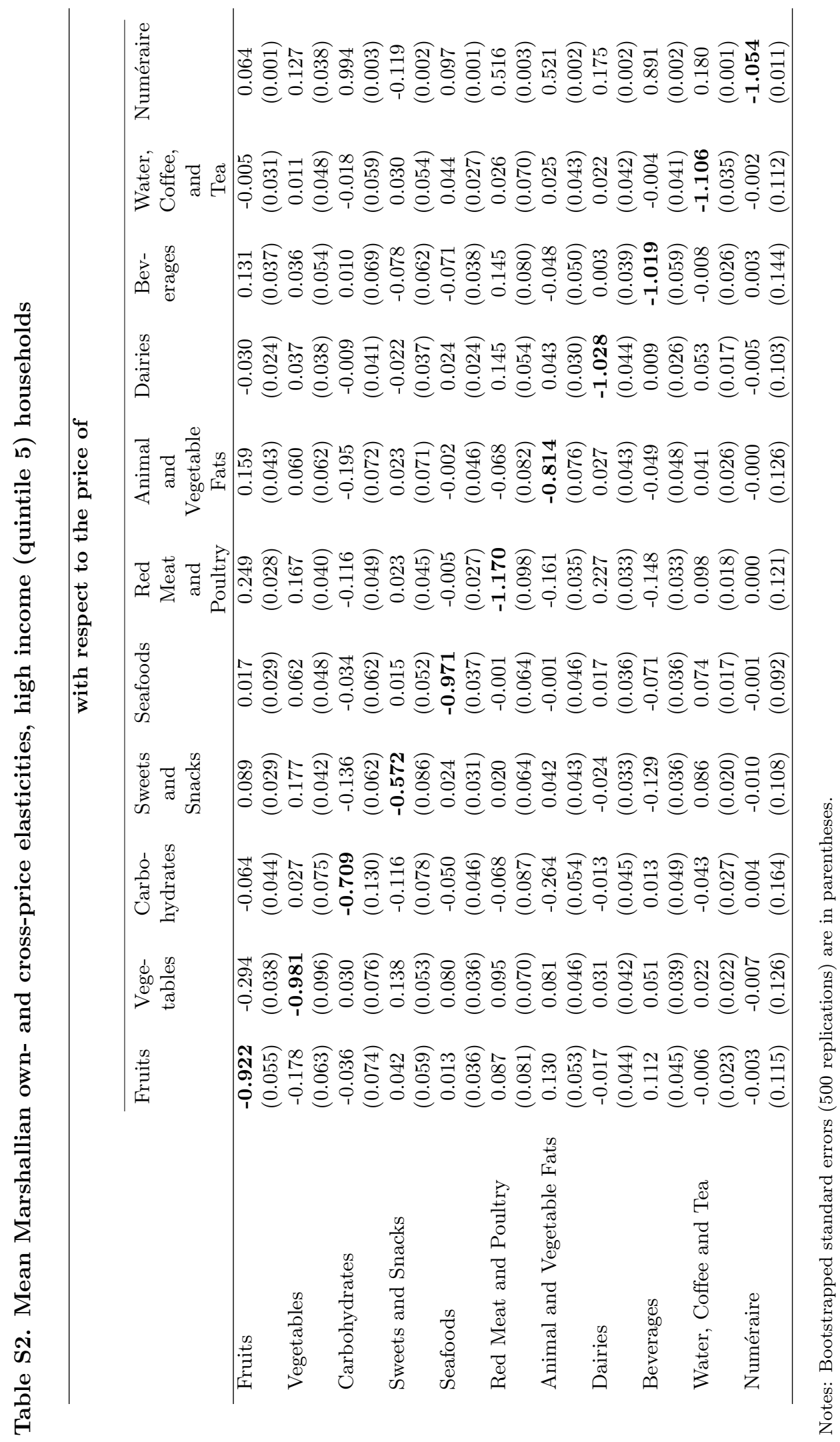


Table S3. Estimated Compensating Variation (CV) assuming incomplete pass-through of taxes/subsidies in prices, by income quintiles

\begin{tabular}{|c|c|c|c|c|}
\hline & \multicolumn{4}{|c|}{ Pass Through } \\
\hline & \multicolumn{2}{|c|}{$75 \%$ Taxes /Subsidies } & \multicolumn{2}{|c|}{$75 \%$ Taxes $/ 50 \%$ Subsidies } \\
\hline & USD & $\%$ of Income & USD & $\%$ of Income \\
\hline \multicolumn{5}{|c|}{ Policy 1: $18 \%$ Tax on Junk Foods $+5 \%$ additional tax on SB } \\
\hline \multirow[t]{2}{*}{ Quintile 1} & 3.27 & 0.75 & 3.27 & 0.75 \\
\hline & $(0.06)$ & $(0.01)$ & $(0.06)$ & $(0.01)$ \\
\hline \multirow{2}{*}{ Quintile 2} & 4.52 & 0.48 & 4.52 & 0.48 \\
\hline & $(0.08)$ & $(0.01)$ & $(0.08)$ & $(0.01)$ \\
\hline \multirow[t]{2}{*}{ Quintile 3} & 5.73 & 0.39 & 5.73 & 0.39 \\
\hline & $(0.10)$ & $(0.01)$ & $(0.10)$ & $(0.01)$ \\
\hline \multirow[t]{2}{*}{ Quintile 4} & 7.53 & 0.33 & 7.53 & 0.33 \\
\hline & $(0.12)$ & $(0.01)$ & $(0.12)$ & $(0.01)$ \\
\hline \multirow[t]{2}{*}{ Quintile 5} & 11.85 & 0.20 & 11.85 & 0.20 \\
\hline & $(0.20)$ & $(0.00)$ & $(0.20)$ & $(0.00)$ \\
\hline \multicolumn{5}{|c|}{ Policy 2: $19 \%$ Fruits/Vegetables VAT Reduction } \\
\hline \multirow[t]{2}{*}{ Quintile 1} & -4.01 & -0.92 & -2.67 & -0.61 \\
\hline & $(0.07)$ & $(0.02)$ & $(0.05)$ & $(0.01)$ \\
\hline \multirow[t]{2}{*}{ Quintile 2} & -5.00 & -0.53 & -3.34 & -0.35 \\
\hline & $(0.09)$ & $(0.01)$ & $(0.06)$ & $(0.01)$ \\
\hline \multirow[t]{2}{*}{ Quintile 3} & -5.67 & -0.39 & -3.78 & -0.26 \\
\hline & $(0.10)$ & $(0.01)$ & $(0.07)$ & $(0.00)$ \\
\hline \multirow[t]{2}{*}{ Quintile 4} & -6.56 & -0.29 & -4.37 & -0.19 \\
\hline & $(0.12)$ & $(0.01)$ & $(0.08)$ & $(0.00)$ \\
\hline \multirow[t]{2}{*}{ Quintile 5} & -9.36 & -0.16 & -6.24 & -0.11 \\
\hline & $(0.18)$ & $(0.00)$ & $(0.12)$ & $(0.00)$ \\
\hline \multicolumn{5}{|c|}{ Policy 3: Tax and Subsidy Together } \\
\hline \multirow[t]{2}{*}{ Quintile 1} & -0.74 & -0.17 & 0.60 & 0.14 \\
\hline & $(0.07)$ & $(0.02)$ & $(0.06)$ & $(0.01)$ \\
\hline \multirow[t]{2}{*}{ Quintile 2} & -0.48 & -0.05 & 1.19 & 0.13 \\
\hline & $(0.09)$ & $(0.01)$ & $(0.08)$ & $(0.01)$ \\
\hline \multirow[t]{2}{*}{ Quintile 3} & 0.06 & 0.00 & 1.95 & 0.13 \\
\hline & $(0.12)$ & $(0.01)$ & $(0.10)$ & $(0.01)$ \\
\hline \multirow[t]{2}{*}{ Quintile 4} & 0.97 & 0.04 & 3.16 & 0.14 \\
\hline & $(0.14)$ & $(0.01)$ & $(0.12)$ & $(0.01)$ \\
\hline \multirow{2}{*}{ Quintile 5} & 2.49 & 0.04 & 5.61 & 0.10 \\
\hline & $(0.23)$ & $(0.00)$ & $(0.20)$ & $(0.00)$ \\
\hline
\end{tabular}

Notes: Bootstrapped standard errors (500 replications) are in parentheses. Positive values denote welfare losses/tax burdens whereas negative values denote welfare gains/subsidy transfers. 